\title{
Adaptive mechanisms of arterial and venous coronary bypass grafts to an increase in flow demand
}

O Gurné, P Chenu, M Buche, Y Louagie, P Eucher, B Marchandise, E Rombaut, D Blommaert, E Schroeder

\begin{abstract}
Objective-To compare the mechanisms by which arterial and venous grafts increase their flow during pacing induced tachycardia, early and later after coronary bypass surgery.

Design-43 grafts (13 epigastric artery, 15 mammary artery, 15 saphenous vein) evaluated early ( 9 (3) days (mean (SD)) after bypass surgery were compared with 41 other grafts (15 epigastric, 11 mammary, 15 saphenous vein) evaluated later after surgery (mean 23 months, range 6 to 168 months) by quantitative angiography and intravascular Doppler velocity analysis during atrial pacing. Controls were 17 normal coronary arteries.
\end{abstract}

Results-Baseline graft flow tended to be lower later after surgery than early (41 (16) $v 45$ (21) $\mathrm{ml} / \mathrm{min}, \mathrm{NS}$ ). Blood flow increased during pacing by 30 (16)\% early after surgery, less than later after surgery (+46 $(18) \%, p<0.001)$ and less than in normal coronary arteries $(+54(27) \%, p<0.001 v$ early grafts; NS $v$ late grafts). There was no difference between venous and arterial grafts. No significant vasodilatation was observed during pacing early after surgery in arterial and venous grafts. Later after surgery, significant vasodilatation was observed only in arterial grafts (mammary and epigastric grafts), from $2.41(0.37)$ to $2.53(0.41) \mathrm{mm}(+5.1 \% v$ basal, $\mathrm{p}<0.001)$. Early after surgery and in venous grafts later after surgery, the increase in flow was entirely due to an increase in velocity. In later arterial grafts, the relative contribution of the increase in velocity to the increase in flow during pacing was lower in arterial grafts $(70(22) \%)$ than in venous grafts $(102(11) \%, p<0.001)$ and similar to normal coronary arteries (68 (28)\%).

Conclusions-Early and later after surgery, arterial grafts and venous grafts both increase their flow similarly during pacing. Early arterial grafts and venous grafts increase their flow only through an increase in velocity. Later after surgery, arterial grafts act as more physiological conduits and increase their flow in the same way as normal coronary arteries, through an increase in velocity and calibre mediated by the endothelium.

(Heart 1999;82:336-342)

Keywords: coronary artery bypass graft; endothelial function
The internal mammary artery is now considered to be the graft of choice for coronary bypass surgery, owing to improvement in long term patency, reduction of cardiac events, and enhanced survival compared with saphenous vein grafts. ${ }^{1-3}$ These favourable results have stimulated research into other arterial conduits, such as the inferior epigastric artery. ${ }^{4-6}$

The higher patency rates of internal mammary arteries have been attributed to histological characteristics, to differences in vascular responsiveness to endogenous agonists, and to the greater capacity of arterial endothelial cells to secrete endogenous dilators. ${ }^{711}$ Studies carried out both in vitro and in vivo have shown that inferior epigastric arteries share some of these favourable properties. ${ }^{12-16}$

There are few data describing the adaptation of these grafts to an increase in myocardial blood flow demand, for example during exercise. Preserved endothelial function in arterial grafts should contribute to the good haemodynamic performance of the graft, allowing it to increase its dimensions when the flow increases. ${ }^{916}$ However, arterial grafts are smaller than venous grafts, which could limit any increase in flow. ${ }^{17}$ Quantitative angiography combined with intravascular Doppler velocity analysis, as validated by Doucette et $a l,{ }^{18}$ can give accurate measurement of absolute blood flow and can be used to study the adaptation of the vessels to an increase in myocardial flow demand. ${ }^{11}$

We designed the present study to evaluate in vivo the mechanisms by which different coronary bypass grafts react during an increase in flow demand induced by rapid atrial pacing. We compared pediculated and free arterial grafts (left internal mammary artery and inferior epigastric artery) and venous grafts, early and later after bypass surgery.

\section{Methods}

PATIENTS

Eighty four patients (72 men, 12 women, mean (SD) age 61 (9) years) were studied during cardiac catheterisation, performed in the context of a systematic angiographic follow up study or of clinical symptoms unrelated to the graft analysed. All vasoactive drugs were stopped one to two days before the study.

Angiographic exclusion criteria for the protocol were diffuse or focal narrowing of the graft, a poor run off, or the presence of severe wall motion abnormalities (akinesia detected by echocardiography or angiography) in the
Accepted for publication 26 March 1999 
Table 1 Demographic characteristics of the patients

\begin{tabular}{|c|c|c|c|c|c|}
\hline & \multicolumn{2}{|c|}{ Early after surgery } & \multicolumn{2}{|l|}{ Late after surgery } & \multirow[b]{2}{*}{$\begin{array}{l}\text { Normal coronary arteries } \\
(n=17)\end{array}$} \\
\hline & $\begin{array}{l}\text { Venous grafts } \\
(n=15)\end{array}$ & $\begin{array}{l}\text { Arterial grafts } \\
(n=28)\end{array}$ & $\begin{array}{l}\text { Venous grafts } \\
(n=15)\end{array}$ & $\begin{array}{l}\text { Arterial grafts } \\
(n=26)\end{array}$ & \\
\hline Age (years) (mean (SD)) & $63(7)$ & $59(10)$ & $65(7)$ & $59(8)^{\star}$ & $60(10)$ \\
\hline Sex & $13 \mathrm{M}, 2 \mathrm{~F}$ & $27 \mathrm{M}, 1 \mathrm{~F}$ & $12 \mathrm{M}, 3 \mathrm{~F}$ & $20 \mathrm{M}, 6 \mathrm{~F}$ & $9 \mathrm{M}, 8 \mathrm{~F}$ \\
\hline Interval after surgery (mean (SD)) & 10 (5) days & 8 (2) days & 34 (44) months & 18 (11) months & - \\
\hline \multicolumn{6}{|l|}{ Risk factors } \\
\hline Hypertension (\%) & 27 & 37 & 27 & 17 & 31 \\
\hline Diabetes mellitus (\%) & 13 & 7 & 7 & 17 & 0 \\
\hline Smoking (\%) & 47 & 59 & 40 & 54 & 43 \\
\hline Family history (\%) & 43 & 66 & 61 & 68 & 42 \\
\hline Plasma cholesterol (mmol/l) & $6.50(1.30)$ & $6.63(1.22)$ & $6.27(0.85)$ & $6.73(0.98)$ & $7.17(0.62)$ \\
\hline \multicolumn{6}{|l|}{ Regional function } \\
\hline Normal (\%) & 67 & 85 & 87 & 72 & 100 \\
\hline Abnormal (\%) & 33 & 15 & 13 & 28 & 0 \\
\hline
\end{tabular}

${ }^{\star} \mathrm{p}<0.05$, arterial $v$ venous grafts.

revascularised areas. All graphs were anastomosed to a native coronary artery with severe stenosis or occlusion.

All patients gave informed consent for the study, and the ethics committee on human research of our institution approved the study protocol.

Forty three patients underwent angiographic evaluation early after bypass surgery (mean (SD), 9 (3) days). In these patients, 13 epigastric artery grafts, 15 mammary artery grafts, and 15 saphenous vein grafts were evaluated. Forty one other patients underwent angiographic evaluation later after surgery (range six to 168 months, mean 23 months). In these patients, 15 epigastric artery grafts, 11 mammary artery grafts, and 15 saphenous vein grafts were evaluated. All the mammary artery grafts were anastomosed to the left anterior descending coronary artery. All epigastric artery grafts and all saphenous vein grafts (except for four late venous grafts which were anastomosed to a marginal branch) were anastomosed to the distal right coronary artery or one of its branches.

The characteristics of the patients are given in table 1. Patients studied late after surgery with arterial grafts were slightly younger than those with venous grafts $(p<0.05)$. There was no major difference in terms of risk factors, regional function, and quality of the run off between early and late grafts. Seventeen patients with normal coronary arteries and normal left ventricular function who underwent the same protocol served as a control group. In this group, 10 left anterior descending coronary arteries, three circumflex coronary arteries, and four right coronary arteries were studied.

\section{STUDY DESIGN}

Coronary angiography was performed by a standard femoral approach. Selective injection of the native coronary arteries and of the grafts was achieved with diagnostic $6 \mathrm{~F}$ catheters. A projection for optimal visualisation of the graft near the centre of the image intensifier field ( 18 $\mathrm{cm})$ was chosen and all subsequent injections were performed according to quantitative angiography standards ${ }^{19}$ : calibration using the empty diagnostic catheter, unchanged single projection throughout the study, and non-ionic contrast medium (Iohexol, $350 \mathrm{mg}$ iodine/100 $\mathrm{ml})$. All angiograms were obtained by manual injection. After injection of a single bolus of 5000 IU heparin, a 0.018 inch $(0.46 \mathrm{~mm})$ Doppler guide wire (Flowire; Cardiometrics Inc, Mountain View, California, USA) was advanced through the $6 \mathrm{~F}$ catheter into the initial portion of the graft, and was adjusted to obtain a good signal of graft blood flow velocity. A $5 \mathrm{~F}$ unipolar pacing wire was placed into the right atrium. Blood flow velocity, arterial blood pressure obtained through the coronary catheter, and the ECG were recorded throughout the study.

The time course of the study protocol was as follows. Measurements of resting coronary blood flow velocity were first obtained at least three minutes after the last contrast injection, as well as a baseline angiogram. Two minutes later, heart rate was increased by atrial pacing to 130 beats $/ \mathrm{min}$. At the end of a two minute period of pacing, blood flow velocity was recorded, and a second angiogram was performed as described by Hanet et al. ${ }^{9}$ Two minutes after the angiography, $2 \mathrm{mg}$ isosorbide dinitrate were directly injected into the graft and one minute later the last angiogram was obtained. Measurements of heart rate and arterial pressure were made immediately before each angiogram.

\section{QUANTITATIVE ANGIOGRAPHIC ANALYSIS}

Quantitative analysis of the grafts was performed with the help of an automated coronary analysis program, with edge contour detection, implemented in the Cardiac Work Station (Philips, Eindhoven, Netherlands) connected with the Digital Cardiac Imaging System (Philips) of our catheterisation laboratory.

The first well opacified end diastolic frame, detected by simultaneous ECG recording, was selected for analysis. The lumen diameter of the same vessel segment, identified with the help of anatomic reference points and taken at the level where blood velocity was recorded, was measured using automated contour detection algorithms. For safety reasons, these measurements were performed in the proximal part of the graft. Absolute dimensions were calculated by reference to the known size of the shaft of the empty catheter, measured $2-3 \mathrm{~cm}$ away from the tip positioned within the ostium of the graft. The cross sectional area of the graft was computed, assuming it to be circular. The 
ratio between the graft diameter, measured 2-3 $\mathrm{cm}$ proximal to the distal anastomosis, and the host coronary vessel at the level of the graft anastomosis was also calculated. The precision and variability of such measurements have been reported previously. ${ }^{18}$ The precision and short term variability of measured vessel dimensions have been evaluated in our laboratory in 23 patients, ${ }^{16}$ with two angiograms obtained three minutes apart. The mean (SD) difference in lumen diameter measured from the repeated angiograms was $-0.03(0.08)$ $\mathrm{mm}$. The intraclass correlation coefficient was 0.994 .

FLOW VELOCITY MEASUREMENTS

All bypass flow velocity measurements with the Doppler guide wire were performed as previously described. In brief, the 0.018 inch guide wire has a $12 \mathrm{MHz}$ piezoelectric ultrasound transducer at its distal tip and permits recording of flow velocity from the frequency shift between the transmitted and returning signals. Time averaged and instantaneous peak velocity values are processed by a computer using fast Fourier transformation techniques, displaying a grey scale depiction of all velocities recorded in the sample volume at one point in time. Bypass blood flow was estimated, as previously validated by Doucette et $a l,{ }^{18}$ as the product of average velocity and cross sectional area. Average peak velocity was calculated on line by the system, and average velocity was derived as average peak velocity divided by 2 , by assuming a time averaged parabolic velocity profile across the vessel.

Increases in velocity and in flow during pacing were determined by calculating the ratio between velocity and flow at the end of the pacing and their respective values at rest. They are expressed as percentages. The relative contribution of the increase in velocity to the increase in flow during pacing was evaluated by calculating the ratio between the pacing to rest velocity ratio and the pacing to rest flow ratio, which are expressed as percentages. In 11 other patients, we assessed the stability and reproducibility of velocity and flow measurements during 20 minutes with a similar protocol. ${ }^{11}$ Flow measurement variability between two measurements of blood flow with a 20 minute interval was $4 \%$, mainly because of the variability of measurements of the vessel dimensions, as velocity remained practically unchanged.
STATISTICAL ANALYSIS

All data are expressed as mean (SD), except on the figures where they are represented as mean with SEM.

Comparison of baseline haemodynamic and angiographic data between the early and the late postoperative period were made using an unpaired Student's $t$ test (two tailed).

The vessel lumen diameters expressed in absolute values and the changes in vessel lumen diameters expressed as a percentage of basal vessel diameter were compared for changes during pacing and after nitrates using one way analysis of variance for repeated measures.

Comparison of changes in velocity and in flow during pacing between the different grafts in the early and in the late postoperative periods, as well comparisons with the normal control coronary arteries, were made using a one way analysis of variance.

Previous data have shown - using only quantitative angiography - that epigastric artery grafts could increase their dimensions during pacing in the same way as mammary artery grafts, and in contrast to saphenous vein grafts. Accordingly, arterial grafts were also combined and compared with venous grafts in this analysis.

Probability $(p)$ values $\geqslant 0.05$ were considered non-significant.

\section{Results}

BASELINE HAEMODYNAMIC CHARACTERISTICS

Baseline haemodynamic and angiographic characteristics of the patients and a comparison between early and later grafts, and between arterial and venous grafts, are shown in table 2. In the basal state, heart rate was slightly higher in early than in later grafts, at 81 (11) v 74 (10) beats/min $(\mathrm{p}<0.05)$, but mean blood pressure was lower early after surgery than later (81 (10) v 103 (15) $\mathrm{mm} \mathrm{Hg}, \mathrm{p}<0.001$ ). Blood haemoglobin concentration was also less in the early group, at $108(10) v 146(16) \mathrm{g} / 1(\mathrm{p}<0.001)$. There was no difference in terms of heart rate, blood pressure, and haemoglobin concentration between late grafts and control normal coronary arteries, or between the different grafts early and late after bypass surgery.

As expected, saphenous vein grafts were much larger both early and later after surgery than arterial grafts. Venous grafts and epigastric artery grafts were larger early than later after surgery: $4.17(0.79) \mathrm{mm}$ in early venous grafts $v 3.29(0.64) \mathrm{mm}$ in later venous grafts $(\mathrm{p}<0.01)$; and $2.64(0.25) \mathrm{mm}$ in early

Table 2 Baseline haemodynamic and angiographic data

\begin{tabular}{|c|c|c|c|c|c|}
\hline & \multicolumn{2}{|l|}{ Early after surgery } & \multicolumn{2}{|l|}{ Late after surgery } & \multirow{2}{*}{$\begin{array}{l}\text { Normal coronary arteries } \\
(n=17)\end{array}$} \\
\hline & Venous grafts $(n=15)$ & Arterial grafts $(n=28)$ & Venous grafts $(n=15)$ & Arterial grafts $(n=26)$ & \\
\hline Heart rate (beats/min) & $82(13)$ & $80(11)$ & $74(11)$ & $75(9)$ & $73(12)$ \\
\hline Mean blood pressure $(\mathrm{mm} \mathrm{Hg})$ & $79(9)^{\star \star \star}$ & $82(14)^{\star \star \star}$ & $103(18)$ & $103(14)$ & $102(8)$ \\
\hline Haemoglobin $(\mathrm{g} / \mathrm{l})$ & $106(7)^{\star \star \star}$ & $108(12)^{\star \star \star}$ & $142(19)$ & $149(10)$ & $138(4)$ \\
\hline Proximal graft diameter (mm) & $4.17(0.79)^{\star \star \star},+十 \dagger$ & $2.51(0.36)$ & $3.29(0.64)++\dagger$ & $2.41(0.37)$ & $2.93(0.58)$ \\
\hline Graft/coronary ratio & $1.68(0.75)+\dagger$ & $1.27(0.26)^{\star}$ & $1.5(0.4)++\dagger$ & $1.1(0.3)$ & - \\
\hline Average peak velocity $(\mathrm{cm} / \mathrm{s})$ & $14(7)^{\star},+\dagger \dagger$ & $26(10)$ & $21(10)$ & $25(8)$ & $25(9)$ \\
\hline Basal flow (ml/min) & $56(19)+\dagger$ & $40(18)$ & $50(16)+\dagger$ & $36(14)$ & $50(23)$ \\
\hline
\end{tabular}

Values are means (SD).

${ }^{\star} \mathrm{p}<0.05,{ }^{\star \star \star} \mathrm{p}<0.001$, early $v$ late after surgery.

$\dagger+\mathrm{p}<0.01,+\dagger+\mathrm{p}<0.001$, venous $v$ arterial grafts. 


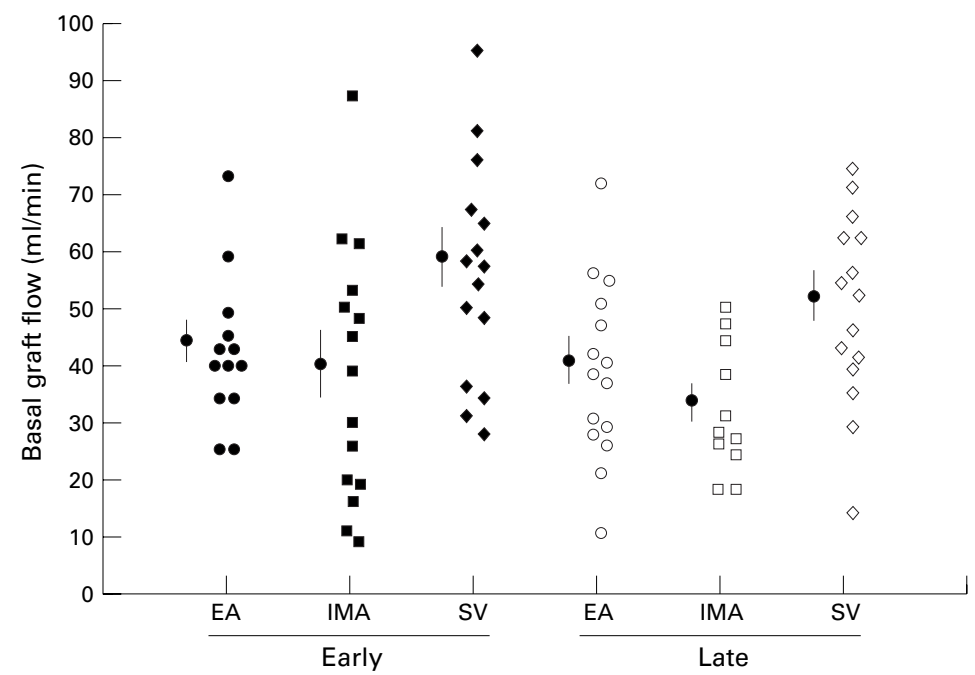

Figure 1 Comparison between baseline graft flow in epigastric artery (EA), internal mammary artery (IMA), and saphenous vein grafts (SV) in the early and late postoperative period.
( $\mathrm{p}<0.01 v$ basal) (fig 2). Normal coronary arteries increased their dimensions similarly during pacing $(+0.16(0.12) \mathrm{mm}, \mathrm{p}<0.001 \mathrm{v}$ baseline). In contrast, no vasodilatation during pacing was observed in saphenous vein grafts at the later time.

Blood flow increased by 30 (16)\% early after surgery, significantly less than later after surgery $(+46(18) \%, \mathrm{p}<0.001)$ or in normal coronary arteries $(+54(27) \%, \mathrm{p}<0.001 v$ early grafts; NS $v$ late grafts). There was no difference in this increase in flow during pacing between venous and arterial grafts early and late after surgery (fig 3). Accordingly, because vasodilatation was observed only in arterial grafts, velocity increased less in arterial grafts than in venous grafts late after surgery $(+34$ (16) $\% v+45(18) \%, p<0.001)$. No difference was observed in this increase in velocity early after surgery between arterial and venous grafts $(+26(15) \% v+28(20) \%$, NS).

Early after surgery, the increase in flow was entirely caused by an increase in velocity in both arterial and venous grafts (fig 4). Late after surgery, the relative contribution of the increase in velocity to the increase in flow during pacing was less in arterial grafts $(70(22) \%)$ than in venous grafts $(102(11) \%, p<0.001)$, where the increase in flow was still entirely attributed to an increase in velocity. Arterial grafts, from this point of view, were similar to normal coronary arteries (68 (28)\%). In mammary artery grafts, the relative contribution of the increase in velocity to the increase in flow during pacing was less than in epigastric artery grafts $(57(12) \% \quad v 80(22) \%, p<0.05)$ but both were less than in venous grafts $(\mathrm{p}<0.001$ for mammary artery grafts; $\mathrm{p}<0.01$ for epigastric artery grafts) (fig 4).

During pacing, there was no significant change in mean arterial blood pressure. No significant vasodilatation during pacing was observed early after surgery in either arterial or venous grafts (fig 2). However, later after surgery significant vasodilatation during pacing was only observed in arterial grafts, where mean diameter increased from $2.41(0.37)$ to 2.53 (0.41) $\mathrm{mm}(+5.1 \%$ vasal, $\mathrm{p}<0.001)$. This increase was slightly but not significantly greater in mammary artery grafts than in epigastric artery grafts: $+0.15(0.07) \mathrm{mm}$ $(\mathrm{p}<0.01 v$ basal $) \quad v+0.10 \quad(0.11) \mathrm{mm}$

RESPONSE TO NITRATES

Early after surgery, significant vasodilatation was observed in mammary artery grafts $(+14 \%, \mathrm{p}<0.001)$ but not in epigastric artery grafts. Later after surgery, significant vasodilatation was observed in epigastric artery grafts $(+12 \%, \mathrm{p}<0.001)$ and in mammary artery grafts $(+16 \%, \mathrm{p}<0.001)$ but not in venous grafts (fig 2). The vasodilatation observed in mammary artery grafts was not statistically different from that observed in epigastric artery
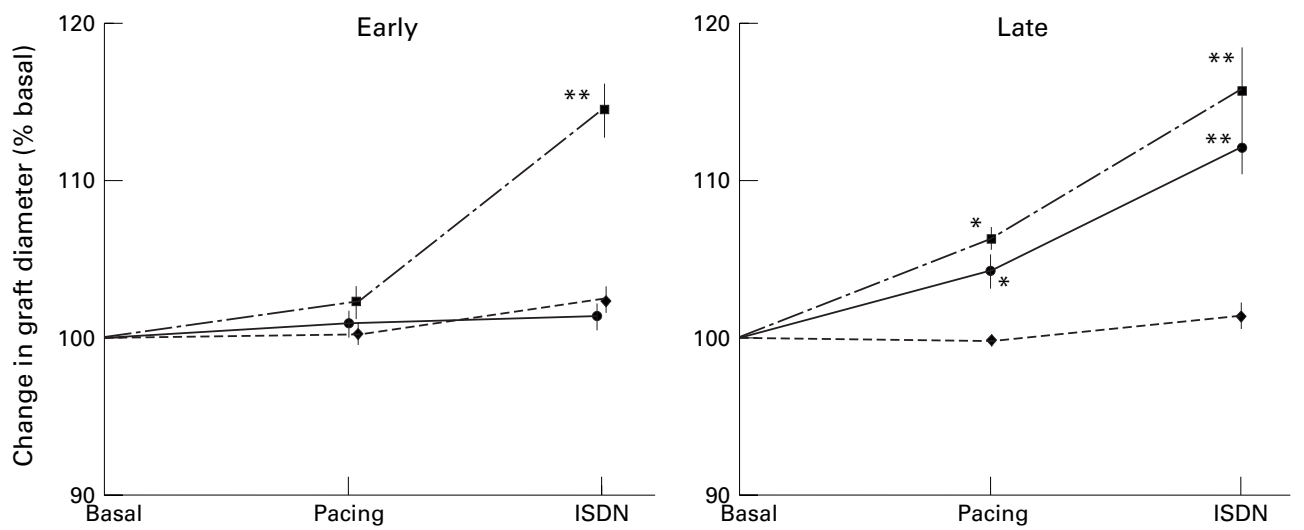

Figure 2 Changes in mean graft diameter, expressed in per cent of basal diameter, observed after pacing and after isosorbide dinitrate (ISDN) injection, in the early (left) and late (right) postoperative period $\left({ }^{*} p<0.01\right.$ and $\star * p<0.001)$, in saphenous vein grafts $(\bullet)$, epigastric artery grafts $(\bullet)$ and mammary artery grafts $(\bullet)$. 


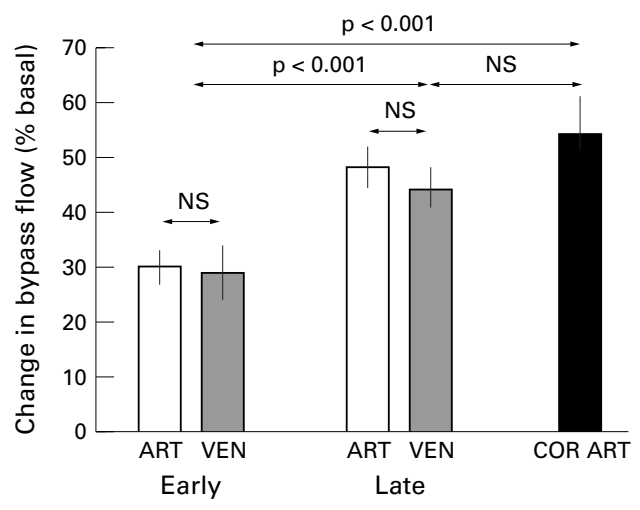

Figure 3 Comparison of increase in flow during pacing, expressed as per cent of basal flow between arterial (ART) and venous (VEN) graphs early and late after surgery, and normal coronary arteries (COR ART).

grafts but was slightly greater than in normal coronary arteries $(+10 \%, \mathrm{p}<0.001 v$ basal; $\mathrm{p}<0.05 v$ mammary artery grafts).

\section{Discussion}

During the past decade, attempts to improve later results of coronary artery bypass surgery have focused on the extended use of arterial conduits, based on the superiority of the internal mammary artery in terms of late patency rate and clinical results. ${ }^{1-3}$ However, little is known about the mechanisms of adaptation of these grafts to an increase in flow demand. Recent work has shown that internal mammary and epigastric arterial grafts, in contrast to saphenous venous grafts, have the ability to increase their dimensions during pacing, owing to preserved endothelial function. ${ }^{91116}$ This phenomenon is seen only later after surgery, and not in the early postoperative period. ${ }^{11} 16$

\section{MECHANISMS OF FLOW ADAPTATION DURING} PACING

Our present data clarify the mechanism by which the different grafts increase their flow. Early after surgery, both arterial and venous grafts increase their flow by increasing the flow velocity, without concomitant flow mediated vasodilatation. Later after surgery, arterial

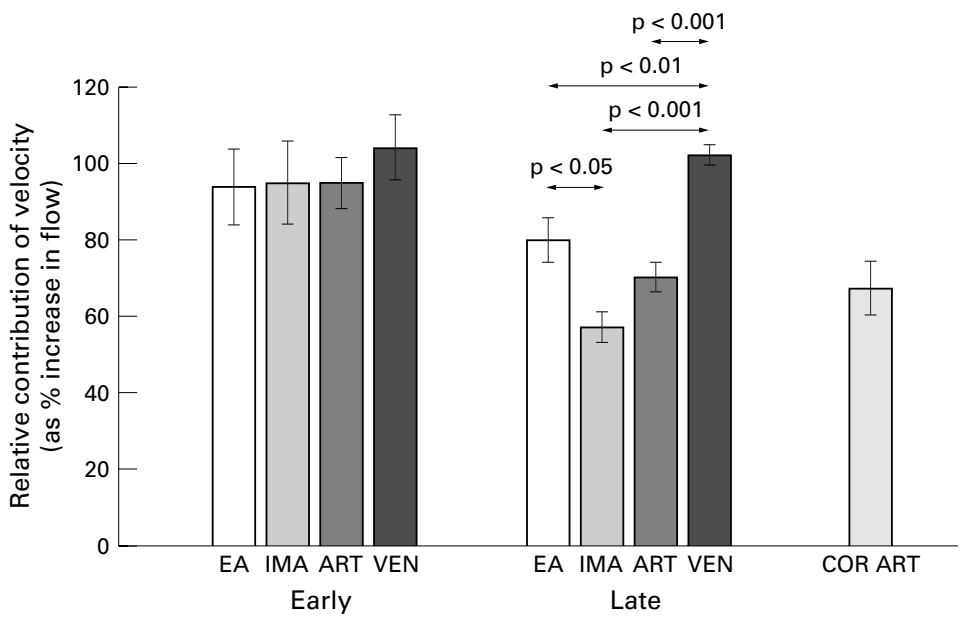

Figure 4 Comparison of the contribution of the increase in velocity to the increase in flow during pacing between early and late grafts ( $E A$, epigastric artery grafts; IMA, left internal mammary artery graft; $A R T$, arterial grafts (epigastric + mammary); VEN, saphenous vein grafts) and normal coronary arteries (COR ART). grafts increased their flow by increasing both flow velocity and luminal diameter. In contrast, venous grafts increased their flow only by an increase in velocity.

Flow mediated vasodilatation may allow arteries to accommodate increased blood flow without an excessive increase in flow velocity or shear stress. This decrease in shear stress during daily exercise could result in a less turbulent flow, reducing damage to the vascular endothelium. The vicious circle of increase flow velocity and increased shear stress may at least partly explain why atherosclerosis, once present, tends to be a progressive disease. ${ }^{20}{ }^{21} \mathrm{It}$ is well known that endothelial dysfunction can be present at early stages, and is correlated with the presence of risk factors for atherosclerosis.

We were interested to note the similarity between the flow adaptation of the pediculated internal mammary artery graft and the free epigastric artery graft. A similar flow mediated dilatation was observed in both grafts. This is consistent with the hypothesis that regulation is predominantly local, mediated mainly by the endothelium and unrelated to innervation. ${ }^{162223}$ In the light of this hypothesis, Kushwaha et al studied endothelial function in mammary artery grafts with substance $P$ and found no significant difference in endothelium dependent and endothelium independent vasodilator responses between free and pedicled internal mammary artery grafts. ${ }^{24}$ Furthermore, arterial grafts have the theoretical advantage of restoring a more physiological blood supply, similar to the mechanism of adaptation of a normal coronary artery in which flow increases by a combination of increased velocity and increased dimensions (fig 3). ${ }^{25}$ Chronic arterial grafts are living conduits with preserved vasomotion, which should have a favourable effect on their haemodynamic performance. From this point of view, the response of arterial grafts to nitrates is interesting, as it shows that these grafts still have a very large dimensional reserve which should allow them to increase bypass flow further if needed. However, no vasodilatation with nitrates was observed in saphenous vein grafts in our study, confirming previous work of Hanet et al. ${ }^{9}$ Morphological changes in these transposed veins have been described, such as intimal thickening, partial replacement of medial smooth muscle cells by fibrous tissue and collagen, and a marked increase in the adventitia in fibrous tissue, with severe disruption or complete replacement of elastic fibres. ${ }^{26}$ All these factors are considered to markedly increase the stiffness of the vein graft and thus may reduce its vasodilator responsiveness to nitrates.

Furthermore, in contrast to studies in vitro, where isolated vascular rings are studied after having been stretched and allowed to equilibrate at the optimal point of their length-tension relation, the basal level of circumferential tension of vascular smooth muscle is determined in vivo by the diameter of the vessel and transmural pressure, according to Laplace's law. There was no difference in arterial blood pressure between patients 
with arterial and venous grafts, but as the diameter of saphenous vein grafts is considerably greater than that of arterial grafts, parietal tensions must be higher for a given blood pressure in venous grafts. The absence of vasodilatation of vein grafts after nitrates could thus also reflect the inability of the vascular smooth muscle layer of saphenous vein grafts to counteract these high circumferential tensions in basal conditions and to maintain some vasodilator reserve.

The situation is probably different for epigastric grafts. We have shown previously in a larger group of patients that early after surgery epigastric grafts anastomosed to a larger run off have a very low basal vasomotor tone and cannot respond to nitrates by further dilatation. ${ }^{6}$ This maximum vasodilatation already present at rest could be an early adaptation to meet the increased flow related to myocardial requirements. A significant vasodilatation with nitrates has only been seen in epigastric artery grafts with a less important run off. ${ }^{6}$ Later after surgery this relation between the quality of the graft run off and the response to nitrates disappeared and a similar vasodilator capacity was seen in all epigastric artery grafts. ${ }^{6}$ In mammary artery grafts, in contrast, a vasodilator response was already present early after surgery and remained unchanged later.

ADEQUACY OF FLOW SUPPLY DURING PACING Concerns have nevertheless been raised about the ability of arterial grafts to provide adequate flow supply at periods of peak myocardial demand. ${ }^{17}$ Arterial grafts are narrower than saphenous vein grafts, and might have greater resistance to coronary blood flow. In the perioperative period, clinical conditions suggesting inadequate perfusion by mammary grafts have been reported by Jones et al and Von Segesser et al. ${ }^{27}{ }^{28}$ Akasaka et al also reported a smaller flow velocity reserve in mammary grafts studied at one month after surgery than in older mammary grafts and in venous grafts studied early and later after surgery, using intravascular Doppler and intravenous infusion of dipyridamole. ${ }^{29}$ Kawasuji et al, ${ }^{30}{ }^{31}$ using radionuclide ventriculography monitoring during exercise, reported a higher proportion of patients with a decrease in regional left ventricular ejection fraction-suggesting inadequate flow for maximal demand-in patients with arterial grafts than in patients with venous grafts.

In contrast, in our study, the relative increase in flow during pacing was similar in arterial and venous grafts, both early and later after surgery (fig 3). This increase in flow was less in the early than in the later postoperative period and in normal coronary arteries. Baseline flow did not differ early and later after surgery, though a non-significant trend towards a higher baseline flow was observed in grafts in the early postoperative period (fig 1). Even though heart rate was higher and haemoglobin concentration lower-both factors that may increase basal blood flow early after surgery-blood pressure was also lower and this would tend to counteract those effects. The lesser increase in flow during pacing early after surgery than later most probably reflects some degree of myocardial stunning after ischaemic cardiac arrest (despite cardioplegia), or residual hibernating myocardium after the revascularisation procedure.

It must be emphasised that, as in the study from Akasaka et $a l,{ }^{29}$ the increase in velocity during pacing was less in arterial grafts than in venous grafts, but this does not mean a reduced performance of the arterial grafts. In fact, the increase in flow in our study, which in arterial grafts combines an increase not only in velocity but also in dimensions, was similar in arterial and in venous grafts. We have recently shown, using a combination of intravascular Doppler and quantitative angiography, that mammary grafts restore a normal flow reserve, estimated after papaverine injection, similar to that measured in normal coronary arteries. ${ }^{11}$ This illustrates the need to combine both velocity and dimensions in evaluating the haemodynamic performance of a graft.

One possible limitation of our study was the fact that the different grafts were inserted into different arterial beds. Mammary grafts were all anastomosed to the left anterior descending coronary artery because of the good results published with this conduit in comparison with saphenous vein grafts. Epigastric artery grafts and venous grafts were anastomosed mainly to the right coronary artery, as in our institution most patients have a second mammary graft inserted into the circumflex artery. To overcome this difficulty, we used relative increase in velocity and flow to express our data. The responses to pacing are thus compared with baseline on an individual basis. One argument for using this methodology could be the consistency that we obtained between the increase in flow in arterial and venous grafts, both early and later after surgery, and between later grafts and normal coronary arteries.

However, in absolute values, graft flow at baseline and during pacing was slightly greater in venous grafts than in arterial grafts. As these patients had no signs of ischaemia either at rest or during a stress test, at least in the areas supplied by the graft, this discrepancy between arterial and vein grafts most probably reflects a difference in the run off of the grafts. As shown by Louagie et al, using a pulsed Doppler flow meter intraoperatively in a larger group of patients, ${ }^{32}$ similar blood flows are observed in venous grafts and in mammary grafts anastomosed to the left anterior descending coronary artery. In a multivariate analysis, the same investigators identified the peripheral resistance of the graft as being the major factor influencing flow through the internal mammary arteries. ${ }^{33}$ Coronary flow is adapted to the metabolic needs of the heart and this adaptation is effected mainly by modifications of coronary resistance. In our study, it was very difficult to make exact comparisons of the importance of the run off of the graft; this depends on many factors including the quality of the distal coronary vessel and competitive flow through native coronary arteries. Furthermore, the function of the areas revascularised 
by the grafts, or some degree of hypertrophy, could also play a role. Small demographic differences between the various groups - such as a slightly older age in the later venous grafts (in comparison with later arterial grafts) and a tendency for a higher prevalence of diabetes mellitus, which can induce microvascular myocardial dysfunction-could also cause some variation in coronary flow. These factors probably explain the apparent discrepancy between flow in absolute values in arterial and venous grafts, which disappears when the relative increase in flow during pacing is analysed.

CONCLUSIONS AND CLINICAL IMPLICATIONS

Quantitative angiography combined with intravascular Doppler velocity analysis appears to be a reliable technique for studying the haemodynamic performance of bypass conduits. From a functional point of view, late arterial grafts seem to be more physiological: they increase their flow in the same way as normal coronary arteries by combined increases in velocity and dimensions, through preserved endothelial function. In this aspect, epigastric artery grafts, despite being free grafts, seem to function nearly as well as mammary artery grafts, which are pediculated. Further long term clinical and angiographic follow up studies are required to determine whether these characteristics of epigastric artery grafts result in a higher patency rate than with vein grafts, and to further define the true efficacy of this form of arterial graft.

We thank the staff of the cardiac catheterisation laboratory for their continued support during this study, Pascal Vantrimpon $M D$ and Claude Hanet MD for reviewing the manuscript, and Mrs Marie-Paule Heylens for typing the manuscript.

1 Grondin CM, Campeau L, Lespérance J, et al. Comparison of late changes in internal mammary artery and saphenous vein grafts in two consecutive series of patients 10 years vein grafts in two consecutive series of patients 10 year 2 Loop FD, Lytle BW, Cosgrove DM, et al. Influence of the internal mammary artery graft on 10 years surviva

3 Zeff RH, Kongtahworm C, Lannone LA, et al. Internal mammary artery versus saphenous vein graft to the left anterior descending coronary artery: prospective randomized study with 10 year follow-up. Ann Thorac Surg 1988;45:533-6

4 Puig L, Ciongolli W, Cividanes GV, et al. Inferior epigastric artery as a free graft for myocardial revascularization. $\mathcal{F}$ Thorac Cardiovasc Surg 1990;99:251-5.

5 Buche M, Schoevaerdts JC, Louagie Y, et al. Use of the inferior epigastric artery for coronary bypass. $\mathcal{F}$ Thorac Cardiovasc Surg 1992;103:665-70.

6 Gurné O, Buche M, Chenu P, et al. Quantitative angiographic follow-up study of the free epigastric angiographic follow-up study of the free epigastric
coronary bypass graft. Circulation 1994;90(suppl II):IIcoronary

7 Lüscher TF, Diederich D, Siebenmann R, et al. Difference between endothelium-dependent relaxation in arterial and in venous coronary bypass grafts. $N$ Engl $\mathcal{F}$ Med 1988;319: $462-7$.
8 Werner GS, Buchwald A, Kreuzer $\mathrm{H}$, et al. Evidence in vivo of an intact endothelial function in internal mammary arteries before and after implantation as coronary grafts. Coron Artery Dis 1990;1:461-8.

9 Hanet C, Schroeder E, Michel X, et al. Flow-mediated vasomotor response to tachycardia of the human internal mammary artery and saphenous vein grafts late following bypass surgery. Circulation 1991;84(suppl III):III-268-74.

10 Lüscher TF, Yang Z, Oemar BS. Endothelium and vascular smooth muscle function of coronary bypass grafts. In: Lüscher TF, Turina M, Braunwald E, eds. Coronary artery graft disease. New York: Springer-Verlag, 1994:193-211.

11 Gurné O, Chenu P, Polidori C, et al. Functional evaluation of internal mammary artery bypass grafts in the early and late
postoperative period. $7 \mathrm{Am}$ Coll Cardiol 1995;25:1120-8.

12 postoperative period. F Am Coll Cardiol $1995 ; 25: 1120-8$. anatomic studies of various arterial conduits for myocardial anatomic studies of various arterial conduits for myocardial

revascularization. F Thorac Cardiovasc Surg 1990;99:703-7.
13 Van Son JAM, Smedts F. Histology of the internal mammary artery versus the inferior epigastric artery. Ann Thorac Surg 1992;53:1147-52.

14 Mügge A, Barton MR, Cremer J, et al. Different vascular reactivity of human internal mammary and inferior epigastric arteries in vitro. Ann Thorac Surg 1993;56:1085-9.

15 Tadjkarimi S, Chester AH, Borland JAA, et al. Endothelial function and vasodilator profile of the inferior epigastric artery. Ann Thorac Surg 1994;58:207-10.

16 Gurné O, Chenu P, Buche M et al. Flow-mediated vasodilation during pacing of the free epigastric artery bypass graft early and late postoperatively. $\mathcal{F}$ Am Coll Cardiol 1996;27: 415-20.

17 Loop FD, Thomas JD. Hypoperfusion after arterial bypass grafting. Ann Thorac Surg 1993;56:812-13.

18 Doucette JW, Corl D, Payne H, et al. Validation of a Doppler guidewire for intravascular measurement of coronary artery flow velocity. Circulation 1992;85:1899-911.

19 Reiber JH, Serruys PW, Kooijmans CJ, et al. Approaches towards standardization in acquisition and quantification of arterial dimensions from one angiogram. In: Reiber JCM, Serruys PW, eds. State of the art in quantitative coronary angiography. Boston: Martinus Nijhoff, 1986:145-71.

20 Lee RT, Loree HM, Fishbein MC. High stress regions in saphenous vein bypass graft atherosclerosis lesions. $\mathcal{f} \mathrm{Am}$ Coll Cardiol 1994;24:1639-44.

21 Vita JA, Treasure CB, Ganz P, et al. Control of shear stress in the epicardial coronary arteries of humans: impairment by atherosclerosis. F Am Coll Cardiol 1989;14:1193-9.

22 Holtz J, Förstemann U, Pohl V, et al. Flow-dependent, endothelium mediated dilation of epicardial coronary arteries in conscious dogs : effects of cycloxygenase inhibition. 7 Cardiovasc Pharmacol 1984;6:1161-9.

23 Joannides R, Haefele WE, Linder L, et al. Nitric oxide is responsible for flow-dependent dilatation of human peripheral conduit arteries in vivo. Circulation 1995;91:1314-19.

24 Kushwaha SS, Bustami M, Tadjkarimi S, et al. Late endothelial function of free and pedicled internal mammary artery grafts. $\mathcal{F}$ Thorac Cardiovasc Surg 1995;110:45362.

25 Nabel EG, Selwyn AP, Ganz P. Paradoxical narrowing of atherosclerotic coronary arteries induced by increases in heart rate. Circulation 1990;81:850-9.

26 Spray TL, Roberto WC. Changes in saphenous veins used as aorto-coronary bypass grafts. Am Heart $\mathcal{F}$ 1977;94:50016.

27 Jones EL, Lattouf OM, Weintraub WS. Catastrophic consequences of internal mammary artery hypoperfusion. $\mathcal{F}$ Thoquences of internal mammary artery hy

28 Von Segesser L, Simonet F, Meier B, et al. Inadequate flow after internal mammary coronary artery anastomoses. $\mathcal{F}$ Thorac Cardiovasc Surg 1987;35:352-4.

29 Akasaka T, Yoshikawa J, Yoshida K, et al. Flow capacity of internal mammary artery grafts: early restriction and later mprovement assessed by Doppler guidewire. Comparison with saphenous vein grafts. F Am Coll Cardiol 1995;25:640-7.

30 Kawasuji M, Tsujiguchi $\mathrm{H}$, Tedorija $\mathrm{T}$, et al. Evaluation of postoperative flow capacity of internal mammary artery. 7 Thorac Cardiovasc Surg 1990;99:696-702.

31 Kawasuji $M$, Tedoriya $T$, Takemura $\mathrm{H}$, et al. Flow capacities of arterial grafts for coronary bypass grafting. Ann Thorac Surg 1993;56:957-62.

32 Louagie YAG, Haxhe JP, Jamart J, et al. Intraoperative Louagie YAG, Haxhe JP, Jamart J, et al. Intraoperative
assessment of coronary artery bypass grafts using a pulsed assessment of coronary artery bypass grafts using a p

33 Louagie YAG, Haxhe JP, Jamart J, et al. Peroperative hemodynamic study of left internal mammary artery grafts. Thorac Cardiovasc Surg 1995;43:27-34. 